\title{
Illegible handwriting and other prescription errors on prescriptions at National District Hospital, Bloemfontein
}

\author{
H. Brits ${ }^{a *}$, , A. Botha ${ }^{a}$, L. Niksch ${ }^{a}$ iD, R. Terblanchéa $i D$, K. Venter ${ }^{a}$ and G. Joubertb \\ ${ }^{a}$ Department of Family Medicine, University of the Free State, Bloemfontein, South Africa \\ ${ }^{b}$ Department of Biostatistics, University of the Free State, Bloemfontein, South Africa \\ *Corresponding author, email: britsh@ufs.ac.za
}

Background: It is generally accepted that doctors have illegible handwriting. The writer usually knows what is written, but other parties often have problems with reading and interpreting.

Aim: The aim of the study was to determine whether illegible doctors' handwriting and other factors that can lead to dispensing errors occur on prescriptions at National District Hospital.

Method: In part one the prescriptions of 20 doctors were read by five doctors, nurses and pharmacists to detect who could read it most accurately. In part two, these doctors were asked to write a prescription with an IntelliPen ${ }^{\circledast}$.

Results: From the 300 measurements, $88 \%$ of the doctors read the prescriptions correctly, compared with $82 \%$ of the nurses and $75 \%$ of the pharmacists. A potential fatal error was lorazepam injection $4 \mathrm{mg}$, which was read as $40 \mathrm{mg}$ (lethal dose) by $20 \%$ of healthcare workers (HCWs). With the IntelliPen ${ }^{\circledast}$ only $39 \%$ of the prescriptions were readable. Only $65 \%$ of prescribers could be identified from their handwriting or the name stamp used.

Conclusion: Pharmacists read the prescriptions worst and they are the people who must dispense the prescriptions. Some of the reading mistakes were critical and could be lethal. Many of the prescriptions did not meet the legal requirement for prescriptions.

Keywords: digital pen, errors, handwriting, prescriptions, reading

\section{Introduction}

It is generally accepted that doctors have illegible handwriting. ${ }^{1}$ The writer usually knows what is written, but when other parties are involved they often have problems reading and interpreting the text. ${ }^{2}$ The following quote stresses the problem with illegible handwriting: 'Doctors' sloppy handwriting kills more than 7000 people annually.' ${ }^{\prime 3}$ An example of this was found in the British Medical Journal where it was reported that a 42-year-old American died after the pharmacist issued Isordil ${ }^{\circledR}$ which he interpreted as Plendil $^{\circledR}$ as a result of the doctor's illegible handwriting. The doctor, a cardiologist, appeared in court and had to pay compensation to the family of the deceased. ${ }^{4} \mathrm{~A}$ study published in 1998 found that even when doctors were asked to write as neatly as possible, their handwriting was still more illegible than those of people in other professions. ${ }^{5}$ In 2002, a study found that $15 \%$ of clinical notes were so illegible that the meaning was unclear. ${ }^{2}$

Very little is published on the handwriting of doctors in South Africa, but one study found that medications used by anaesthesiologists were not legible in $26.5 \%$ of cases. ${ }^{6}$

Preventable medication errors affect more than 1.5 million Americans annually. These errors are caused by unclear abbreviations and doses, and illegible handwriting. Therefore a plea has been made for doctors to use digital notes and prescriptions to prevent these errors. ${ }^{3}$ However, some research studies have indicated that electronic prescriptions do not prevent common prescription errors made in manual handwritten prescriptions. ${ }^{7}$ Regardless of the computer revolution, most information in clinical records is still written by hand.
The IntelliPen ${ }^{\circledast}$ Pro (Anabelle Bits Pty Ltd, Australia) is a digital pen that is able to process and store written words and pictures in digital format. An electronic receiver is attached to the paper written on and then one writes with the IntelliPen ${ }^{\circledR}$ on the paper. The receiver stores the information in a 'memory stick', which can then be read on a computer. The IntelliPen ${ }^{\oplus}$ works with ultrasonic acoustic waves and the movement of the pen. The transmitter, which is inside the pen, constantly sends signals to the receiver, which processes the written words into digital data. ${ }^{8}$

\section{Aim and objectives}

The aim of the study was to determine whether illegible doctors' handwriting and other factors that can lead to dispensing errors occur on prescriptions at National District Hospital, Bloemfontein.

The objectives of the study were:

- to assess the readability of doctors' handwriting on prescriptions in National District Hospital;

- to determine which group of health care workers (HCWs) could read the prescriptions best;

- to identify other factors on prescriptions that could contribute to dispensing errors;

- to determine whether the use of an IntelliPen ${ }^{\circledast}$ increases the readability of doctors' handwriting.

\section{Methodology}

This study consisted of two major parts. In part one the prescriptions of selected doctors were read by different groups of health care workers to detect who could read it most accurately. Reasons for inaccurate reading were also investigated. 
In part two the doctors who wrote the prescriptions were asked to write a prescription with an IntelliPen ${ }^{\circledast}$. These prescriptions were then printed in electronic format and the number of mistakes with digital processing was calculated.

The target population consisted of doctors at National District Hospital, Bloemfontein, who wrote the prescriptions and the doctors, nurses and pharmacists who interpreted these prescriptions. National District Hospital is a district hospital and part of the academic training complex in Bloemfontein. The hospital consists of a casualty department, 197 inpatient beds, a theatre and an outpatient clinic. The Department of Family Medicine trains doctors and students in the facility and there are consultants (9), registrars (3), medical officers (8), community service doctors (6) and interns (10) rotating on the platform.

Twenty doctors working in the National District Hospital were randomly selected from the call schedules to participate in the study. After they gave informed consent their first prescription dispensed at the pharmacy, on a date agreed by the hospital administration, was selected for inclusion in the study.

Five doctors, nurses and pharmacists each were randomly selected using simple random sampling from personnel lists to interpret the prescriptions. An appointment was made with the selected doctors, pharmacists and nurses to read the prescriptions at a time not interfering with normal work schedules. A senior physician checked each item on the prescription and controlled it with the prescriber before the information was added onto a specific data form for each prescription. After informed consent each of the participants was asked to read the prescriptions to two researchers. The researchers audiotaped the responses and also controlled what was read with what was actually written on the prescription on the data form.

For each prescription, the name of the medication, medication strength, dosage, dosage interval, route of administration and duration of treatment were checked. Omissions on the prescriptions were also noted. Each drug on the prescription was interpreted separately. If more than five items were written on a prescription, only the first five were included in the study for logistical reasons. Data were coded according to a system where ' 0 ' was given for an incorrect reading and ' 1 ' for a correct reading.

The two researchers then compared the data forms and if any discrepancies occurred or any data form was not completed fully they listened to the audiotapes to verify the information.

The second part of the study involved the same doctors in the sample who wrote the prescriptions, who after informed consent were then asked to write the letters of the alphabet, numbers from zero to nine and medical notes with the IntelliPen ${ }^{\circledast}$. The doctors received clear instructions on the basic use of the IntelliPen ${ }^{\oplus}$, e.g. to ensure that the light on the pen was on, indicating that it was recording. Only the single letters, numbers and the sentence, e.g. 'Ibuprofen, orally, $400 \mathrm{mg}$ 6-8 hourly with meals', were interpreted for readability. After conversion of the written text to digital data, a code block was filled for each letter, number and word in the sentence, again using ' 0 ' and ' 1 '.

After data cleaning the Department of Biostatistics, University of the Free State, analysed the data and reported the results as percentages, frequencies means or medians. SAS ${ }^{\circledR}$ Version 9.2 (SAS Institute, Cary, NC, USA) was used for all data management and analysis.
To minimise methodology and data collection errors the following steps were taken:

- Data on the prescriptions were verified with the writer.

- Data forms were numbered and controlled by two researchers.

- Data were gathered by two researchers and verified with audiotapes.

- The doctors were asked to write a paragraph, but only the prescription part was interpreted to try and prevent them writing differently from normal.

- Care was taken that the IntelliPen ${ }^{\circledR}$ recorded the writing, to prevent missing data.

A pilot study was carried out on five prescriptions and no change was made to the data collection forms. During the pilot study the time to read the prescriptions, as well as for the doctors to write with the IntelliPen ${ }^{\oplus}$, was estimated to plan the main study. The efficiency and quality of the audio recordings of the prescriptions were also determined. Technical problems with the batteries for the IntelliPen ${ }^{\circledast}$ were sorted out. These data were not included in the main study as the number of people that read each prescription differed from the main study.

Permission was obtained from the Ethics Committee, Faculty of Health Sciences of the University of the Free State, and the Head of Health, Free State Department of Health to perform the study. All information and data were managed confidentially. Participation in the study was voluntary and all participants gave written consent.

\section{Results}

There were 20 prescriptions each read by five doctors, five nurses and five pharmacists to give a total of 300 prescription readings. Each prescription contained between two and five items (83 in total) and a total of 385 measurements occurred on the 20 prescriptions.

\section{Reading errors}

Overall the doctors read the prescriptions best with a median correct percentage of $87.8 \%$ compared with $81.8 \%$ of the nurses and $75 \%$ of the pharmacists. Mistakes occurred with all the specific items checked on the prescriptions. Overall mistakes occurred on $18.5 \%$ of prescriptions, indicating that health care workers could read $82 \%$ of prescriptions without any mistake. In Figure 1 the percentages of mistakes per category for the different HCWs are displayed. Only the name of the medication, dosage and dosage interval are displayed as some HCWs omitted to read the duration and route of administration, although this was on the prescription.

Important errors identified were cefuroxime $750 \mathrm{mg}$ that was read as $250 \mathrm{mg}$ by $67 \%$ of HCWs. This would be an insufficient dosage for the severity of the infection that was treated. Lorazepam injection $4 \mathrm{mg}$ was read as $40 \mathrm{mg}$ (which is a lethal dose) by $20 \%$ of HCWs.

\section{Other factors}

Another problem identified was that on only $65 \%$ of prescriptions could the doctor/prescriber be identified from his/her handwriting or name stamp.

The majority of mistakes occurred when doctors used abbreviations to name drugs. Five abbreviations were used and errors occurred with the reading of all of them. Abbreviations 


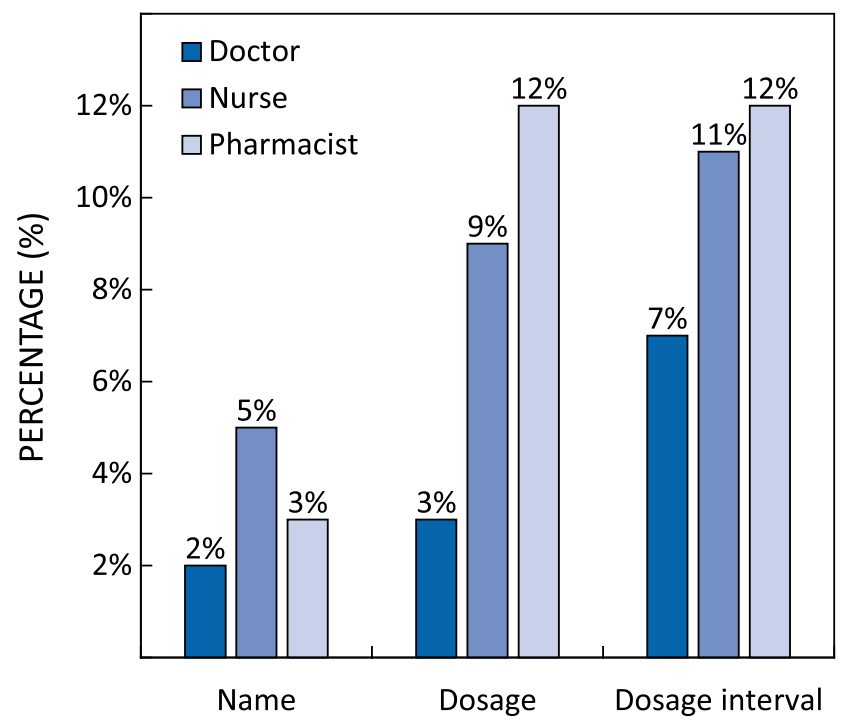

Figure 1: Percentage of errors per prescription.

Table 1: Errors per abbreviation for the different health care workers

\begin{tabular}{lcccc}
\hline Abbreviation & $\begin{array}{c}\text { Doctor } \\
(\boldsymbol{n}=5)\end{array}$ & $\begin{array}{c}\text { Nurse } \\
(\boldsymbol{n}=5)\end{array}$ & $\begin{array}{c}\text { Pharmacist } \\
(\boldsymbol{n}=5)\end{array}$ & Total \\
\hline $\begin{array}{l}\text { UMS (ung methyl } \\
\text { salicylate) }\end{array}$ & $0(0 \%)$ & $0(0 \%)$ & $1(20 \%)$ & $7 \%$ \\
$\begin{array}{l}\text { ATT (anti tetanus } \\
\text { toxoid) }\end{array}$ & $0(0 \%)$ & $0(0 \%)$ & $3(60 \%)$ & $20 \%$ \\
$\begin{array}{l}\text { AR Vax (anti } \\
\text { rabies vaccine) }\end{array}$ & $0(0 \%)$ & $2(40 \%)$ & $2(40 \%)$ & $27 \%$ \\
$\begin{array}{l}\text { HCTZ (hydrochlo- } \\
\text { rothiazide) }\end{array}$ & $1(20 \%)$ & $3(60 \%)$ & $0(0 \%)$ & $27 \%$ \\
\begin{tabular}{l} 
AAS (aspirin) \\
\hline
\end{tabular} & $1(20 \%)$ & $3(60 \%)$ & $0(0 \%)$ & $27 \%$ \\
\hline
\end{tabular}

contributed to $60 \%$ of the name errors. In Table 1 the percentage of errors is displayed per abbreviation used and HCW category.

Generic names of medication were used for only 22 out of 83 (27\%) items prescribed. Only one mistake occurred with a generic name written in full.

Significantly more errors regarding reading of dosage intervals occurred on prescriptions written by left-handed doctors $(17 \%$ versus $9 \%$, chi-square test $p<0.01$ ).

\section{Use of digital equipment}

Twenty prescriptions were written with the Intellipen ${ }^{\oplus}$, one each by the participating doctors. Some $53 \%$ of the letters and $56 \%$ of the numbers were transcribed correctly. The letters misread by the Intellipen ${ }^{\oplus}$ in more than $50 \%$ of cases were A (70\%), L (68\%), $\mathrm{N}(55 \%), \mathrm{U}(70 \%)$ and $\mathrm{Z}(60 \%)$. Only one number was misread more than $50 \%$ of the time, namely 1 (94\%). Errors occurred in all of the prescriptions with the digital transcriptions. The only item that was correctly read in more than $50 \%$ of prescriptions was the dosage interval, namely 8 in 8 hourly.

There was no correlation between the number of errors in the handwritten prescriptions and the digital transcriptions of the prescriptions written by the same doctor. However, the percentage of errors of the two left-handed doctors were $100 \%$ and $78 \%$ respectively when transcribed digitally.

\section{Discussion}

The researchers expected the pharmacists to read the prescriptions best as it is their everyday job to read prescriptions and then to dispense medicine. In this study they read worse than the doctors and the nurses. This result may be due to the fact that the pharmacy personnel were mainly doing Community Service and did not work with the doctors for long periods of time. A study in Saudi Arabia confirmed that expert pharmacists found $2 \%$ of prescriptions difficult to read or illegible, compared with $21.6 \%$ of non-expert pharmacists. ${ }^{9}$ An Italian study also confirmed illegible handwriting in $24 \%$ of prescriptions in a hospital setting. ${ }^{10}$ On the other hand the doctors indicated that they were able to read the prescription because they knew the handwriting as well as the medication and dosages prescribed. However, pharmacists should also know the medication and dosages that they dispense.

Critical errors occurred on two prescriptions, both dosage errors. A critical error was defined by Mohan et al. as an error that is potentially dangerous if dispensed to a patient and includes name and dosage errors. ${ }^{11}$

The fact that $35 \%$ of doctors could not be identified as the writer of the prescription poses a major problem as the pharmacist could not contact the prescriber to confirm items on the prescription. It is a legal requirement according to the Medicines and Related Substances Act 101 of 1965 (amended) to ensure that the name is legible on all prescriptions. ${ }^{12}$ The absence and/ or illegible handwriting of prescribers are identified in different studies as a source of prescription errors. ${ }^{10,13,14}$

The use of abbreviations for drug names contributed to $60 \%$ of medication name errors. The Australian Commission on Health Care and Quality in Health care stated that no drug name should ever be abbreviated. ${ }^{15}$

The use of trade or brand names instead of generic names is a major concern in many studies and a major contributor to prescription errors. ${ }^{10,11,13,14}$ In this study generic names were used in $27 \%$ of prescriptions, while this contributed to only $2.3 \%$ of the drug name errors. A reason for this confusion may be that the names are shorter and many begin or end with the same letters, e.g. Plendil $^{\oplus}$, Doanil $^{\circledR}$, Amoxil $^{\oplus}$, Isordil ${ }^{\oplus}$.

The transcription of written data into digital data causes more mistakes (63\% vs. $18.5 \%$ ) than the reading of the written prescriptions. A digital pen is therefore not a solution for illegible handwriting.

\section{Conclusion and recommendation}

Health care workers could read $82 \%$ of doctors' handwriting on prescriptions in the National District Hospital without any mistakes. The majority of prescriptions are therefore legible to heath care workers.

Doctors could read the prescriptions best and pharmacists made most errors. This is concerning as they are the people who must dispense the prescriptions.

Other factors identified on prescriptions that could contribute to dispensing errors were the use of trade names and abbreviations for medication and that the prescriber could not be identified. Doctors should refrain from using trade names and abbreviations on all prescriptions and ensure that they can be identified and contacted if the dispenser is uncertain about anything on the prescription. 
The use of the digital pen did not improve the readability of doctors' handwriting and is therefore not recommended.

Doctors should be made aware of the results and consequences of illegible handwriting.

\section{References}

1. Berwick DM, Winickoff DE. The truth about doctors' handwriting: a prospective study. BMJ. 1996;313(7072):1657-8. doi:10.1136/ bmj.313.7072.1657.

2. Rodriguez-Vera FJ, Marin Y, Sanchez A, et al. Illegible handwriting in medical records. J R Soc Med. 2002;95(11):545-6. PMID: 12411618, PMCID: PMC1279250.

3. Caplin J. Cause of death: sloppy doctors. Time Magazine. 2007 Jan 15. Available from: http://content.time.com/time/health/ article/0,8599,1578074,00.html.

4. Charatan F. Family compensated for death after illegible prescription. BMJ. 1999;319:1456. doi:10.1136/bmj.319.7223.1456.

5. Lyons R, Payne C, McCabe M, et al. Legibility of doctors' handwriting: quantitative comparative study. BMJ. 1998;317:863-4. doi:10.1136/ bmj.317.7162.863.

6. Raff M, James MFM. An audit of anaesthetic record keeping. South Afr J Anaesth Analg. 2003;9(3):7-9. doi:10.1080/22201173.2003.10873005.

7. Nanji KC, Rothschild JM, Salzberg C, et al. Errors associated with outpatient computerized prescribing systems. J Am Med Inform Assoc. 2011;18(6):767-73. doi:10.1136/amiajnl-2011-000205.
8. IntelliPen Digital Pen and USB Flashdrive. How does it work? 2010 [cited 2014 Mar 26]. Available from: http://www.intellipen.com.au/ Howdoesitwork.aspx.

9. Albarrak Al, Al Rashidi EA, Fatani RK, et al. Assessment of legibility and completeness of handwritten and electronic prescriptions. Saudi Pharm J. 2014;22:522-7. doi:10.1016/j.jsps.2014.02.013.

10. Calligaris L, Panzera A, Arnoldo L, et al. Errors and omissions in hospital prescription writing in a hospital. BMC Clin Pharmacol. 2009;9(9):6 p. doi:10.1186/1472-6904-9-9.

11. Mohan P, Sharma AK, Panwar SS. Identification and quantification of prescription errors. Med J Armed Forces India. 2014;70(2):149-53. doi:10.1016/j.mjafi.2014.01.002.

12. Medicines and related substances act 101 of 1965 - regulations and notices - government notice R510. Government Gazette 37032. South Africa; 2013. Available from: http://www.saflii.org/za/legis/ consol_reg/marsa10101965rangnr510723/.

13. Fadare JO, Agboola SM, Alabi RA. Quality of prescriptions in a tertiary care hospital in south west Nigeria. J App Pharm Sci. 2013;3(9):81-4.

14. Rambhade S, Shrivastava A, Rambhade A, et al. A survey on polypharmacy and use of inappropriate medications. Toxicol Int. 2012;19(1):68-73. doi:10.4103/0971-6580.94506.

15. Recommendations for terminology, abbreviations and symbols used in health care. The Australian Commission on Health Care and Quality in Health care; 2011. [cited 2016 Mar 5]. Available from: https://www. safetyandquality.gov.au/wp-content/uploads/2012/01/32060v2.pdf.

Received: 24-08-2016 Accepted: 24-10-2016 